\title{
O BULLYING NAS SÉRIES INICIAIS DO ENSINO FUNDAMENTAL
}

\author{
Darley Kury Marques de Amorim ${ }^{1}$ \\ Deysiane Silva da Luz Oliveira ${ }^{2}$ \\ Marelucia Rodrigues de Amorim ${ }^{3}$ \\ Mayara Almeida Gomes ${ }^{4}$ \\ Sandra Gusmão de Almeida ${ }^{5}$
}

RESUMO: O conceito de Bullying envolve desde dar apelido, tirar sarro, desprezar, as chacotas infantis, até as maneiras mais violentas de agressividade física ou mental. Bullying é o fenômeno através uma criança ou um adolescente é de modo sistemático onde é colocado diante de várias ações agressivas (diretamente ou indiretamente), que acontecem sem motivação visível, mas de maneira intencional, praticados por um(a) ou mais agressor(es). Trata-se de ação realizada em grupo tendo como característica desequilibrar o poder e falta de reciprocidade; onde, a vítima não tem mecanismo para que possa impedir e/ou escapar a agressão. O que essencialmente caracteriza essa agressão de outras é a repetição, sistematização e a intencionalidade de provocar prejuízo a alguma pessoa que normalmente é entendido como tem mais fragilidade, sendo difícil conseguir sua defesa ou até mesmo que se reverta esse fato. $O$ bullying é um perigo, uma violência institucional e social, assim como para comportamentos antissociais individuais significando uma maneira de afirmar o poder que se estabelece por meio da agressão.

Palavras-chave: Bullying. Violência Institucional e Social. Agressão. Agressor.

ABSTRACT: The concept of Bullying ranges from giving nicknames, making fun, scorning childish teasing, to the most violent forms of physical or mental aggression. Bullying is the phenomenon through which a child or adolescent is systematically placed in front of various aggressive actions (directly or indirectly), which happen without visible motivation, but intentionally, practiced by one or more aggressor(s)). It is an action performed in a group with the characteristic of unbalancing power and lack of reciprocity; where, the victim has no mechanism to prevent and/or escape the aggression.

\footnotetext{
I Graduada em Pedagogia pela Fundação Universidade Federal de Mato Grosso do Sul - FUFMS, Especialista em Educação Infantil e Alfabetização pelo Instituto Cuiabano de Educação - ICE.

${ }^{2}$ Graduada em Pedaogia pelo Centro Universitário de Várzea Grande - UNIVAG.

3 Graduada em Pedagogia pela Universidade Estadual do Tocantins - UNITINS, Especialista em Atendimento Educacional Especializado pela Fundaçao Universitária Iberoamericana - FUNIBER.

${ }_{4}$ Graduada em Pedagogia pela Universidade de Cuiabá - UNIC, Especialista em Educação Infantil e Alfabetização pela Faculdade Afirmativo.

${ }_{5}$ Graduada em Pedagogia pelo Centro Universitário de Várzea Grande - UNIVAG, Especialista em Gestão e Segurança Pública pela Universidade do Estado de Mato Grosso - UNEMAT.
} 
What essentially characterizes this aggression from others is the repetition, systematization and intention of causing harm to someone who is normally understood to have more fragility, making it difficult to get their defense or even to reverse this fact. Bullying is a danger, an institutional and social violence, as well as for individual antisocial behavior meaning a way to assert the power that is established through aggression.

KEYWORDS: Bullying. Institutional and Social Violence. Aggression. Aggressor.

\section{INTRODUÇÃO}

O presente artigo tem como tema: Bullying, sendo este considerado um problema presente em praticamente todas as escolas, públicas ou privadas. Como linha de pesquisa docência séries iniciais do ensino fundamental.

A escolha por este tema justifica-se na medida em que o bullying é um problema que precisa combatido, nos seus mais variados modos: condutas agressivas, intencionais e realizadas repetidamente, ocorrendo sem ou com motivos aparentes, assumida por um ou mais pessoas contra o outro, gerando sofrimentos.

Ao pensar acerca do valor desse tema, é necessário ao educador para que este possa intervir na sala de aula criando estratégias para evitar e combater o bullyng, pois este não pode ser encarado como algo normal. Este problema sempre existiu, entretanto, seu agravamento cada dia mais vem intensificando no ambiente escolar, acarretando problemas emocionais, intelectuais, econômicos, para os alunos e sua família.

\section{DESENVOLVIMENTO}

Para Torquato (2013, p. 9) as escolas tendem a não aceitarem a existência do bullying; não reconhecem e não enfrentam esse problema, sendo que esse modo de agressão comumente acontece, incluindo os apelidos pejorativos usados para humilhar os colegas.

Este fenômeno relaciona-se as dificuldades emocionais de cada agressor, sendo que na família desses agressores existe a história de violência associada, onde a criança com comportamentos agressivos vive a violência muito próxima.

O contato diário com a violência é um modo que os agressores têm conhecimento, onde a sensação de poder é que motiva o agressor. São Pessoas que não tem uma convivência familiar, necessário para lidarem com situações de problemas. Geralmente 
encontramos três tipos de pessoas que se envolvem nesse modo de violência: espectador, vítima e agressor.

\begin{abstract}
A vítima do Bullying muitas vezes acaba sendo excluída de um grupo ou ate mesmo se excluindo, por temer agressões e exposições ao ridículo, por sentir-se fragilizada ou por não ter segurança de revelar o problema sofrido. Assim pode apresentar problemas psicológicos e ter alterações em seu comportamento (COSTA, 2oir, p. 7)
\end{abstract}

Diante desse panorama, é possível constatar que as relações familiares passam por transformações, e o efeito mais evidente desse fato é o afastamento entre os pais e filhos no dia a dia.

Entretanto, é de suma importância que os pais encontrem tempo para conviverem de modo saudável com seus filhos e a escola tem papel essencial no desenvolvimento intelectual psicológica do aluno.

Lopes Neto (2005) nos adverte acerca de um novo modo de intimidação, que ele denomina de cyberbullying, é o emprego da tecnologia da comunicação (celulares e internet, entre outros) para a prática deste modo de violência.

A falta de atenção de professores e funcionários escolares com relação a esse fenômeno é algo grave, pois, ocasiona a evasão escolar de muitos alunos que por não conseguirem se defender termina deixando de irem para a escola.

Marriel (2006, p. 37) considera como um dos alicerces básicos do bullying escolar a relação entre à discriminação e à intolerância ao outro. Temos dessa forma a discriminação de gênero (meninos contra meninas), de raças (contra negros, índios), social, (ricos vistos como esnobes ou pobres), alunos novatos, ou outro estereótipo, (gordinho, magricela, afeminado).

\footnotetext{
O bullying pode ser entendido como um balizador para o nível de tolerância da sociedade com relação à violência. Portanto, enquanto a sociedade não estiver preparada para lidar com o bullying, serão mínimas as chances de reduzir as outras formas de comportamentos agressivos e destrutivos (LOPES NETO, 2005, p. I70).
}

Segundo Pinheiro (2006) o comportamento violento está dividido em dois grupos: o primeiro faz referência às ações diretas físicas (chutar, empurrar, bater, tomar pertences) e verbais (apelidos e insultos); o segundo as ações indiretas/emocionais por meio de boatos. A prática verbal é a mais comum, onde a função exercida no bullying pode ser 
modificada pelas características daqueles envolvidos, a pessoa não é fundamentalmente a vítima ou o agressor.

[...] os alunos vitimados tornam-se agressores, agressores passam a ser vitimados, e o desrespeito move-se furtivamente das relações entre alunos para as relações entre alunos e professores, e então para as interações entre professores e alunos (BEAUDOIN \& TAYLOR, 2006, p. 18).

De acordo com Egea (apud Pinheiro, 2006, p. 9) a violência causa no ambiente escolar um local de hostilidade, favorecendo um clima de aula de tensão e ocasionando maus relacionamentos estabelecidos entre os alunos e professores.

Assim sendo, como decorrências, o desconhecimento desse problema ou a falta de ações eficazes contra o bullying, resultam num clima de insegurança, tensão e estresse, tornando a escola completamente inadequada, sendo que todos os alunos são prejudicados, desenvolvendo um comportamento ansioso, de medo e de agressividade, e isso independe do envolvimento da pessoa, se está em atitudes agressivas, essas ações resultam em marcas intensas ocasionando em frustrações e condutas mal adaptadas.

As consequências do bullying escolar são diversas e extensamente documentadas na literatura (e. g. Menesini, Modena, \& Tani, 2009; Olweus, 2013; Rigby, 2003; Stassen Berger, 2007). Swearer et al. (2011) citaram alguns dos principais efeitos da vitimização, tais como solidão, maior evitação da escola, ideação suicida, baixa autoestima, depressão, ansiedade, problemas físicos de saúde e baixo rendimento acadêmico. Para os agressores, as autoras apontaram maior risco de problemas de conduta, envolvimento com delinquência e condenação por crimes na vida adulta. As vítimas-agressoras, por sua vez, foram consideradas o grupo em maior vulnerabilidade, com maior risco de diagnóstico de hiperatividade, depressão, baixo engajamento acadêmico e indicação para tratamento psiquiátrico (SANTOS, et al. 2015, p. 1019).

Para Rozek \& Viegas (2012, p. 74), o “bullying” pode ser difícil de combater, porque, mesmo que comece como brincadeira, o poder que surge em dominar uma criança mais fraca pode ser recompensador.

O primeiro-passo a ser assumido para que se possa intervir, combater e prevenir contra a violência e a discriminação escolar é conscientizar os pais e professores para que possam ensinar às crianças o cultivo do respeito ao próximo, tolerância com o diferente, ensinando que "ser diferente" não é sinônimo de ser inferior, pois o diálogo dos professores com os alunos também se torna de extremo valor no combate e no combate da violência escolar. 
A escola representa um extraordinário contexto de interação social, que tem importância na constituição dos seres humanos como indivíduos e cidadãos, deste modo, precisando ser um ambiente seguro e saudável. Atualmente, um fenômeno desagradável e que ameaça os objetivos da escola tem chamado a atenção de toda a sociedade.

O bullying está em todo lugar, acontece, sobretudo nas escolas, afetando uma parcela significativa de alunos, elevando-se, assim, a incidência de transtornos que podem levá-los até mesmo a deixar de frequentar as aulas. Entre suas consequências, estão alterações negativas no rendimento escolar dos indivíduos, bem como em seu comportamento.

As consequências de âmbito psicológico ou social mais comumente atribuídas às vítimas são diminuição ou perda da autoestima, aumento do sentimento de insegurança, elevação da ansiedade e depressão. Além disso, a sensação de insegurança que se cria tende a diminuir o interesse pelo ensino e a motivação para frequentar as aulas, comprometendo, assim, o rendimento, a aprendizagem e a frequência escolar e provocando, por sua vez, evasão, nervosismo, dificuldade de concentração e até mesmo possibilidades de automutilação e tendências suicidas (SANTANA E SILVA; COSTA, 2016, p. 643).

Dessa forma, é imprescindível, contudo, delicada a identificação do bullying e dos seus personagens, dadas as suas consequências. Distinguir-se-á claramente e com notas individualizantes este fenômeno de outros modos de violência, bem como das demais condutas desviantes. O bullying ameaça o desenvolvimento saudável dos sujeitos envolvidos e não é um fenômeno natural para a formação dos mesmos, ao contrário do que diz a crença popular.

Ventura \& Fante (2013), afirmam que estamos diante da carência de valores, guias do comportamento, decorrente da modernidade.

[...] do contexto escolar, as falas sobre o bullying parecem constituir um emblemático representante da contemporaneidade na escola a aglutinar uma série de expectativas, propostas de intervenção e prevenção, valores e atitudes de enfrentamento $e$, por conseguinte, processos de subjetivação. Em última instância, trata-se de uma das versões do mal-estar contemporâneo que privilegia a escola como espaço-tempo para a sua expressão (CANAVÊZ, 2015, p. 272).

Existem várias definições para bullying, dentre as quais, podemos citar: "O bullying é um comportamento agressivo repetido, que pode se revestir de várias formas e que ocorre no âmbito de um desequilíbrio de poder físico e/ou psicológico entre o agressor e a vítima" (VENTURA \& FANTE, 2013, p. 22). 
Segundo Silva (2010, p. 2I) a palavra bullyng é de origem inglesa, correspondendo a um conjunto de atitudes de violência física e/ou psicológica que acontecem nas instituições de ensino. As crianças e jovens que são vítimas de bullying, na maioria, sofrem em silêncio diante o comportamento de seus agressores. Os resultados são desastrosos, indo desde repetência e evasão escolar até isolamento, depressão e, em casos extremos, suicídio e homicídio.

Para Olweus (1993, p. 9) apud Ventura \& Fante (2013): “um estudante está sendo vítima de bullying quando ele ou ela é exposto, repetidamente e de forma sustentada, a ações negativas por parte de um ou mais estudantes”.

Olweus foi o primeiro estudioso a adotar o bullying como objeto de investigação científica, em seus estudos realizados na Escandinávia e Noruega nos anos finais da década de 70.

No Brasil, a educadora Cleo Fante realizou os primeiros estudos brasileiros acerca do assunto entre os anos de 2000 e 2003 em instituições educativas, públicas e privadas, de cidades do interior de São Paulo, por meio da Abrapia. A amostra de alunos pesquisados era formada de alunos freqüentes entre os $6^{\circ}$ e $9^{\circ}$ anos do ensino fundamental, cujos resultados deram origem a um projeto de combate ao bullying chamado Educar Para a Paz.

Somente em 2009, foi realizada uma pesquisa que abrangesse todo o território nacional. A ONG Plan Internacional Brasil foi a propulsora desta pesquisa que apresenta um diagnostico, no mínimo, alarmante das escolas brasileiras, como se pode observar nas conclusões a seguir, além de outras que podem ser encontradas no site da ONG:

- As escolas apresentam uma "atmosfera" violenta, tornando-se, assim, um ambiente desconfortável;

- 70\% dos 5168 estudantes que participaram da pesquisa presenciaram situações violentas no ano letivo de 2009;

- $23 \%$ dos alunos protagonizaram o bullying mais de três vezes no ano letivo em questão, sendo I0\% vítimas, a mesma porcentagem autores e 3\% vítimas autoras;

- Adolescentes do $7^{\circ}$ ano e com idades entre ir e is anos sofrem mais intimidações, em relação aos demais; 
- ${ }_{12,5 \%}$ dos meninos são vítimas do bullying, enquanto as vítimas do sexo feminino representam $7,6 \%$ do total de meninas;

- Os cenários mais comuns desta violência são a sala de aula e o pátio de recreio e a mesma se dá, na maioria das vezes, na ausência de adultos.

Essa violência pode manifestar-se sob aspectos diferentes entre si. Com base na obra da psiquiatra Ana Beatriz Barbosa Silva (2010), Bullying: mentes perigosas nas escolas apresentam-se a seguir uma relação das formas como se dá o bullying:

- Verbal: Insultar, ofender, xingar, fazer gozações, apelidar de maneira pejorativa, fazer piadas ofensivas, "zoar";

- Físico e material: Bater, chutar, espancar, empurrar, ferir, beliscar, roubar/furtar/destruir pertences da vítima, atirar objetos contra a vítima;

- Psicológico e moral: Irritar, humilhar e ridicularizar, excluir, isolar, ignorar/desprezar/ fazer pouco caso, discriminar, ameaçar/aterrorizar, chantagear/intimidar, tiranizar, dominar, perseguir, difamar, passar bilhetes e desenhos, de caráter ofensivo, entre colegas, fazer intrigas e fofocas (maior ocorrência entre meninas);

- Sexual: abusar, violentar, assediar, insinuar;

- Virtual: cyberbullying - usar a tecnologia da comunicação, capaz de espalhar rapidamente, para caluniar e difamar; divulgação de imagens, e-mails com teor ameaçador e criação de comunidades são as atitudes mais comuns nestes casos.

Essas atitudes de caráter violento têm seus efeitos colaterais nos sujeitos envolvidos nas agressões. As conseqüências do bullying são tão graves quanto o fenômeno em si, podendo arrastar-se até a vida adulta. Para Silva (2010), os reflexos dos traumas vividos na escola podem durar toda uma existência. "O cerne da questão do bullying encontra-se, exatamente no mesmo nível dos efeitos" (VENTURA \& FANTE, 2013, p. 30).

As principais consequências observadas são: queda no rendimento escolar; dificuldades de concentração e de relacionar-se; efeitos psicossomáticos como dores de 
cabeça, insônia, hematomas sem explicações, enjoo, cansaço, alergias; síndrome do pânico; rejeição/fobia escolar; fobia social (TAS), caracterizado por extrema timidez, ansiedade intensa e elevado temor de ser ridicularizado, podendo apresentar dificuldades ao comunicar-se, como "brancos" e gagueira; Transtorno de ansiedade generalizada (TAG), ou seja, medo e insegurança persistentes e em grau elevado; Depressão, baixa autoestima; Anorexia/bulimia; TOC; Mudanças de humor repentinas; Isolamento; Esquizofrenia e suicídio/homicídio, sendo estes menos frequentes.

Alguns pais tomam atitudes extremas para protegerem os filhos, como mudá-los de turma, escola ou horário, por exemplo. Existem relatos de pais que agrediram os agressores dos filhos. Recentemente, tem se ouvido falar em casos infelizes e gravíssimos de bullying, tal qual o de Realengo, no Rio de Janeiro, o Columbine High School (Colorado EUA) e o ocorrido em Alberta, Canadá, na High School. Estes casos tomaram grandes proporções devido à violência extrema com que aconteceram. Combater o bullying pode evitar crimes.

Assim, faz-se necessária a identificação do bullying pelos profissionais de educação para que sejam elaboradas as estratégias de enfrentamento do problema, envolvendo toda a escola, os pais, os alunos e a comunidade. Esclarecer os conceitos inerentes a este fenômeno é de suma importância, posto a gravidade do fenômeno em si, bem como os seus efeitos, tanto para os envolvidos como para a própria sociedade. Pode-se dizer que, tendo conhecimento do que é o bullying e das suas principais implicações, o próximo passo é identificar a ocorrência do fenômeno e aprofundar, identificando seus personagens, para então tomar as medidas cabíveis.

Silva (2010) aponta a identificação como um fator decisivo para que a missão de erradicar o problema seja cumprida com êxito. Ventura \& Fante (2013) definem os papeis, utilizando o Ciclo do Bullying, que pode ser apreciado em sua obra.

Com esta ferramenta e do uso do discurso correto, pode-se provocar alterações positivas no comportamento das pessoas envolvidas. Dessa forma, os protagonistas são as vítimas, e/ou vítimas agressoras, quando reproduzem os atos violentos sofridos; os agressores e os espectadores.

Embora os profissionais de educação tenham a percepção do ambiente violento em 
que a escola cada vez mais vem se transformando, os mesmos, na maioria das vezes, mostram-se sem preparo para lidarem com o bullying, como afirmam Ventura \& Fante (2013):

Resolver este problema é responsabilidade de toda a sociedade, posto a gravidade do assunto. Pode-se citar ainda que o fenômeno infringe um dos princípios básicos do ensino, previsto em Lei, no Art. $3^{\circ}$ da Lei de Diretrizes e Bases (1996): o respeito à liberdade e apreço à tolerância.

O desenvolvimento de um Projeto de Ensino acerca do bullying é uma alternativa para lidar com ele, pois se trata de um fenômeno que também ocorre na escola. Percebe-se que a sociedade, segundo Ventura \& Fante (2013), formou-se com muitos preconceitos, o bullying, por exemplo, é um processo inerente ao amadurecimento do indivíduo e isso não traz nenhum dano ao mesmo.

Além introduzir novas informações e definições, a eficiência do combate a esta pandemia depende também da reconstrução de alguns conceitos, internalizar um novo modo de pensar é uma tarefa árdua, mas que a escola pode realizar, posto que esteja sempre aberta a novas ideias, sabe ouvir e falar, e sensibilizar-se com os problemas alheios.

Deste modo, é possível afirmar que o bullying é uma epidemia, cuja erradicação é um dever de todos, pois seus danos alcançam a todos, uma vez que os agressores tendem a se tornar delinquentes quando adulto.

Tal fenômeno tem se alastrado por todos os países de forma assustadora, tornando-o uma epidemia mundial. O problema está no fato de sua ação ser tão sutil que passa despercebida ou é então tolerada pela comunidade escolar, e vista, muitas vezes, como normal no relacionamento entre crianças e adolescentes (SEGUNDO, 2015, p. 222).

A impunidade tem seus efeitos colaterais. Sabe-se, porém, que práticas intrínsecas relacionadas ao bullying tais como: injúria, calúnia, difamação, agressão física e assédio psicológico e moral são crimes previstos na Constituição. Os educadores devem esclarecer aos alunos envolvidos no bullying e aos pais dos mesmos, com o fim de esclarecer e impedir essa violência.

\section{CONCLUSÃO}

A elaboração deste artigo possibilitou conhecer o Bullying, suas formas de manifestação, consequências, o papel do professor, entre outros. 
Este tema que é relativamente novo, na verdade, a sua prática é tão antiga, porém, nos últimos anos tem tomado grandes proporções.

A intolerância às diferenças tem trazido inúmeros transtornos à sociedade e a violência, na fase escolar, costuma trazer danos desastrosos à vida dos sujeitos, com efeitos negativos no comportamento, estado psicológico e emocional, assim como em sua vida social e se arrastando, muitas vezes até a vida adulta.

As consequências não poderiam ser mais desastrosas para a sociedade, que convive hoje com a intolerância generalizada e com a falta de compaixão e o desrespeito. Neste sentido, o bullying tende a reforçar estes sentimentos e justamente num ambiente em que se prega o contrário.

A escola deve ser a instituição, que além dos ensinamentos didáticos, formem cidadãos solidários e aptos a viverem em sociedade, respeitando e convivendo com as diferenças.

\section{REFERÊNCIAS BIBLIOGRÁFICAS}

CANAVÊZ, Fernanda. A escola na contemporaneidade: uma análise crítica do bullying. Revista Quadrimestral da Associação Brasileira de Psicologia Escolar e Educacional, SP. Volume 19, Número 2, Maio/Agosto de 2015: 271-278. Disponível em: http://www.scielo.br/pdf/pee/vign2/2175-3539-pee-I9-02-0027I.pdf. Acesso em: 25/ro2021.

COSTA, Silvio. Antibullying: uma nova estratégia para aprender e previnir. São Paulo: Paulinas, 20II.

LOPES NETO, Aramis A. Bullying: comportamento agressivo entre estudantes. Jornal dePediatria, 8I (5), I64-172, 2005.

MARRIEL, Lucimar Câmara et al. Violência escolar e auto-estima de adolescentes. Cad.Pesqui., São Paulo, v. 36, n. I27, Apr. 2006. Disponível em http://www.scielo.br. Acesso em 25/10/2021.

PINHEIRO, F.M.F. Violência intrafamiliar e envolvimento em "bullying" no ensinofundamental. Dissertação de Mestrado. São Carlos: UFSCar, 2006. I48p.

ROZEK, Marlene; VIEGAS, LúcianeTorezan. (orgs.) Educação inclusiva: políticas, pesquisa e formação Porto Alegre: EDIPUCRS, 2012. 
SEGUNDO, Paulo Roberto Robles Estebon. Bullying escolar: os danos sociais e os aspectos jurídicos do fênomeno. Educere - Revista da Educação, v. 15, n. 2, p. 219-237, jul./dez. 2015. Acesso em http://revistas.unipar.br. Acesso em 25/ro/2021.

SILVA, Ana Beatriz Barbosa. Bullying: Mentes Perigosas na Escola. Rio de Janeiro: Objetiva, 2oro.

VENTURA, Alexandre. FANTE, Cléo. Bullying: intimidação no ambiente escolar evirtual. Belo Horizonte MG.Editora: Conexa, 2013.

SANTANA E SILVA, Cíntia; COSTA, Bruno Lazzarotti Diniz. Opressão nas escolas: o bullying entre estudantes do ensino básico. Cadernos de Pesquisa v.46 n.161 p.638-663 jul./set. 2016 639http://www.scielo.br/pdf/cp/v46nI6I/198o-5314-cp-46-16r-oo638.pdf

SANTOS, Mariana Michelena. Bullying: Atitudes, Conseqüências e Medidas Preventivas na Percepção de Professores e Alunos do Ensino Fundamental. Trends in Psychology / Temas em Psicologia. 2015, Vol. 23, no 4, 1017-1033. Disponível em http://pepsic.bvsalud.org. Acesso em 25/ro/202I. 